\title{
Metaphors for Educators: A Cultural Cognitive Approach
}

\author{
Mei Tao \\ College of International Studies, Southwest University, Chongqing, China
}

\begin{abstract}
Cognitive Linguistics maintains that metaphor is one of the basic ways of thinking and the cognitive tool for talking about and understanding abstract concepts. The present research focuses on metaphors for educators and attempts to uncover the underlying cognitive mechanism for the metaphorical construe or conceptions of educators. This research is committed to the investigation of the cognitive function of metaphors and attempts to explore and explain the cross-cultural variation and universality between metaphors for educators in Chinese and English through cultural models and cognitive models. This research not only broadens the research perspectives of conceptual metaphor, but also enriches the contents of cross-cultural metaphorical research.
\end{abstract}

Index Terms — educators, conceptual metaphor, cognitive linguistics, cognitive model, cultural model

\section{INTRODUCTION}

Education is always closely connected to metaphor. As an indispensable participant in education activity, educator as a cover term for teacher, instructor, mentor, director, etc., carries types of relevant metaphors which are deeply embedded in cognition and culture. This paper is concerned with metaphors for educators in both Chinese and English.

Previous research on metaphors for educator in educational context mainly focuses on the investigation of historical evolvement (Kasten 1998). The ongoing researches have barely done from the perspective of cognitive basis and cultural cognitive approach. Moreover, few studies and researches are conducted in comparisons of metaphors for educators between different countries cognitively and culturally. The lack of systematicness is the biggest problem.

Talking about cognitive foundation of metaphor, embodied experience and knowledge serve as the basis of metaphors regarded as a way of thinking. They influence the way one acts, thinks and speaks so as to influence his mind about the world (Lakoff \& Johnson 1980). When it comes to cultural cognitive explanation, Gannon (2001) puts metaphor into culture for consideration and puts forward cultural metaphor as a typical symbol of customs to make a distinction between different nations. Ungerer \& Schmid (2013) put forward cognitive models and cultural models. From the perspective of cognitive linguistics, "cognitive model, as the term suggests, represent a cognitive, basically psychological, view of the stored knowledge about a certain field." and "cognitive models can be seen as cognitive models that are shared by people belonging to a social group or subgroup". Still some other researchers also claims that culture play a vital role on metaphor (Kovecses 2005 etc.). Accordingly, metaphors for educator are also cognitive and cultural oriented. Therefore, as a new approach on researches of metaphor for educators, comparisons between Chinese and English educator metaphor on the basis of cognitive cultural approach which would be probed in detail would explore the influence of cognition and culture on educational metaphor, most importantly, will promote the development of teaching and communication between Chinese and Western.

\section{METAPHORS FOR EDUCATORS IN CHINESE AND ENGLISH}

Conceptual Metaphor is the mapping across conceptual domains between two domains: source domain and target domain (Lakoff \& Johnson 1980; Lakoff \& Turner 1989, Sweeter, 1990). In other words, a conceptual metaphor includes four basic elements: source domain, target domain, experience and mapping. Educator refers to someone who educates people, including teacher, professor, mentor, master, etc. Meanwhile, as one of the most important participants in education, educator can tie into almost every facet of education. The EDUCATOR domain consists of such sub-concepts EDUCATOR, EDUCATEE, TEACHING PROCESS, TEACHING EFFECT, TEACHING MEANS, LEARNING, SCHOOL, CLASS, BLACKBORD, CHALK, etc. In those conceptual metaphors for educator concluded below in both Chinese and English, we would find: what kind of source domain can be related to EDUCATOR domain? How can some characteristics of the source domain map onto those of the target domain? What are the cognitive basis and cultural explanations for those metaphors?

As mentioned above, all those data of linguistic metaphors for educators presented in the following mainly are based on some famous people's quotes on teachers, students, education, etc., some authoritative corpus and some internet data.

A. Metaphors for Educators in both Chinese and English

Analyzing data of metaphors for educator in both Chinese and English individually, we found that five conceptual 
metaphors as following are frequently used in both Chinese and English educational context: EDUCATOR IS GUIDE, EDUCATOR IS GARDENER, EDUCATOR IS ARTIST, EDUCATOE IS FEEDER, and EDUCATOR IS STUFFER.

\section{EDUCATORS ARE GUIDES}

In the metaphor EDUCATORS ARE GUIDES, the target conceptual domain EDUCATORS is understood in terms of the source conceptual domain GUIDES. How are mappings between these two conceptual domains established? Guide refers to someone or something that shows the way by leading or advising. Educators are conceived as guide for they share some correlations. Thus in the source domain GUIDES, it contains some concepts such as LEADING/DIRECTING/ACTIVATING, JOURNEY DESTINATION, ENCOUNTERING OBSTACLES, ROUTES etc., all of which can be mapped onto some concepts of the target domain like EDUCATING, PURPOSE OF EDUCATING, ENCOUNTERING DIFFICULTIES, TEACHING APPROACHES, etc. Those concepts can be reflected in following (1) to (4).

(1) 老师是天上最亮的北极星, 为我们指引前方的道。

Teachers are the brightest North Star in the sky, directing our way ahead.

(2) 好的老师是好的舵手, 总能把你人生的小船恰到好处地引向宽阔的水域。

A good teacher is a good coxswain who can always lead your boat of life to open water.

(3) And in language teaching, the idea that the teacher should direct the progress of learners has been questioned on the grounds that such direction impedes the natural process of learning.

(4) If he is indeed wise he does not bid you enter the house of his wisdom, but rather leads you to the threshold of your own mind.

\section{EDUCATORS ARE GARDENERS}

Gardener as a positive image in both Chinese and English has been used as a source domain for many professions due to its connotations of good characters, such as diligence and conscientiousness. In conceptual metaphor EDUCATORS ARE GARDENERS, we compare the educator to gardener for they share some correlated concepts, in other words, the target domain EDUCATORS is understood in terms of the source domain GARDENERS. GARDENING, GARDENS, PLANTS/SEEDS, FRUITE, REAPING HARVEST, etc. as some basic sub-concepts of GARDENERS can be mapped onto some sub-concepts of EDUCATORS such as, TEACHING, UNEDUCATED EDUCATEES, EDUCATED EDUCATEES, SCHOOLS, TEACHING RESULT, etc.

(5) 老师用汗水浇灌了我们, 让我们去的丰收。

Teachers irrigate us with their sweat so that we can reap a harvest.

(6) 小树不修不直溜, 人不修理梗啾啾。

Young trees cannot keep straight if nobody prunes their branches. And young people will make troubles if nobody supervises and instructs them.

(7) The task of the modern educator is not to cut down jungles, but to irrigate deserts.

(8) In school, your teacher is the fruit picker and you are the open fruit basket. EDUCATORS ARE ARTISTS

The famous educator B. A. Cyxomjnhcknn regards schools as instruments which can play beautiful melodies and influence the soul of every student. The only way to play these beautiful melodies is tuning up those instruments by someone who is called "teacher". Thus, teacher can be called an artist as well. When we gather and analyze abundant linguistic metaphors data, other educators in other working areas have this concept in common. Consequently, we have a conceptual metaphor EDUCATOR IS ARTIST here. Some Concepts as ART PROCESSING, RAW MATERIALS, ARTISTIC ACHIEVEMENTS, etc., in the source domain ARTIST can be compared to the corresponding concepts PROCESS OF TEACHING, EDUCATEES, TEACHING RESULTS, etc.

（9）老师是出色的工匠，不拘一格地雕刻着所有雕像。您雕的不只是我们充实的知识，更是我们方正的品格。

Teachers are excellent craftsmen, carving out all the statues without set patterns. In your carving work, you shaped not only our rich knowledge but also our decent personality.

（10）每个孩子都一块块“璞玉”，需要我们去发现他们的价值，进行精雕细玩，让他们成为件件“精品”。

Every child is an uncut jade, waiting for us to discover their value and carve them in an excelsior way so as to make everyone a masterpiece.

(11) His progressive education philosophy, developed in the early 1900s, portrays the teacher as an artist who facilitates the development of the child as artist.

(12) Through her interactions with the children, the teacher is engaged in a continual process of crafting and recrafting the environment, building on their existing collaborative resources, and gradually extending the range of collaboration which children choose and are able to engage in by themselves.

\section{EDUCATOES ARE FEEDERS}

Based on experiences, we usually tend to see getting knowledge as a process of eating. We use many verbs in the EATING category and FEEDING category to depict learning and teaching processes. Probably it has some collections to our cultures of eating. After the analysis of data in English, many linguistic metaphors can be found to describe education as a process of eating and feeding. We conclude a conceptual metaphor EDUCATORS ARE FEEDERS. The source domain FEEDERS can be construed in terms of the target domain EDUCATORS. Some concepts link to the source domain FEEDERS: FEEDING, FOODS, HUNGRY MEN, AFTER FEEDING, etc., in the source domain are understood in terms of concepts like TEACHING, KNOWLEDGE, EDUCATEES, TEACHING RESULTS etc. 
（13）面对“嗷做待哺”的学生，老师应该知道如何去哺育他们。

Teachers are expected to know how to feed starving students.

(14) 我们感谢敬爱的老师，用知识和爱哺育我们成长。

Thanks to our teacher, feeding our growth with knowledge and love.

(15) When we feed students answers instead of strategies, we only provide for one completed written paper.

(16) Spoon feeding in the long run teaches us nothing but the shape of the spoon. EDUCATORS ARE STUFFERS

In our daily activities, we often compare 3ducates to containers. Stuffer draws an image of someone who fills an empty container to be full. Equally, teaching is a process to fill 3 ducates with knowledge or wisdom. Thus, EDUCATORS can be conceived with reference to the conceptual domain STUFFERS. Some target concepts TEACHING, KNOWLEDGE, EDUCATEES in EDUCATORS domain are understood in terms of FILLING, FILLERS, CONTAINERS, etc.

(17) 乡村教师填补了教育达不到的地方。

Village school teachers fills the gap where education cannot reach.

（18）老师把所有精力都倾注在我们身上。

Teachers pour their energy into us.

(19) His job status to how well his students do on tests. It's a teacher's job, Jackson said, to instill students with a desire to succeed.

(20) "In the wild struggle for existence, we want to have something that endures, and so we fill our minds with rubbish and facts, in the silly hope of keeping our place.

\section{B. Chinese-specific Metaphors for Educators}

Although metaphors are pervasive, based on different cultures among countries, there must be some conceptual metaphors for educators that cannot be found in other culture. Culture influence people's thoughts so as to affect the use of metaphors for some specific entities. In China, teachers appear on the stage of history from the primitive society. Kövecses (2005) claimed that conceptual metaphors would change with the change of culture. China has its bright culture and different cultural connotation, so for some concepts Chinese hold different cognitive model and cultural model. After conclusion, we excavate the elaboration of two Chinese metaphors for educators in Chinese only as follows: EDUCATOR IS LIGHT SOURCE, EDUCATOR IS ANIMAL.

EDUCATORS ARE LIGHT SOURCES

Light always brings hope and warmth so the image of light is extremely positive both in China or western countries. On the basis of metaphor data, a conceptual metaphor concluded is EDUCATION IS LIGHT SOURCE which is pervasive in China and rare in English. Light sources can light the way, which is correlated to the process of education. Thus, some concepts CANDLES/LIGHTS/SUN......, LIGHTING/BURNING, DISPELLING DARKNESS, BURNING OUT, BRING WARTH/BRIGHTNESS etc. in the source domain can be mapped onto some related concepts EDUCATORS, TEACHING, SOLVING PROBLEMS, DEDICATING, RESULTS, and TEACHING RESULTS.

（21）老师一只蜡烛, 燃烧自己, 照亮别人。

Teachers are candles, burning themselves, however, illuminating others.

(22) 每一句话, 每一个行为都给学生带去温暖。

They bring the students warmth through their words and behaviors.

(23) 每当我沮丧时, 老师总能如光一样驱散我内心的黑暗。

Teachers are the lights that dispel the darkness inside me whenever I am depressed.

\section{EDUCATORS ARE ANIMALS}

Animal in this dissertation refers to non-human members of creatures. Animals have very close relationship with human beings since human beings appear. In China, animals have rooted deeply in Chinese culture, especially some image of diligent animals are even respected by people. Based on data analysis, we get a conceptual metaphor EDUCATORS ARE ANIMALS. We would construe the target domain ANIMALS in terms of the source domain EDUCATORS. Some concepts OX/COWS/BEES/SILKWORMS..., LABORING, LABORING OBJECTS, OUTPUTS, DEDICATING etc., in the source domain ANIMALS can be compared to these concepts EDUCATORS, TEACHING, EDUCATEES, TEACHING RESULTS, etc., in the target EDUCATORS.

(24) 我们耳濡目染了老师们“俯首甘为擩子牛”的奉献精神。

We are impressed by teachers' dedication like a head-bowed willing ox.

（25）老师是蜜蜂, 辛勤地劳作。

Teachers are bees working diligently.

（26）三尺讲台，传道解惑，春蚕吐丝，烛照人寰。

On the platform, teachers impart knowledge and solve puzzles, like silkworms producing silk and candles lighting for the mankind.

In China, people are inclined to use those animals to compare to educators. During the educating processes, being humble and diligent is vital important and precious character of a good educator. 


\section{English-specific Metaphors for Educators}

Just as China, in western countries, undoubtedly there are some metaphors for educators that cannot match in those of Chinese due to different cognitive model and cultural model. Western countries own its own culture, reflecting its own thinking pattern about something. Different language communities will hold different perception of the world. Some metaphors for educators in English only are concluded into EDUCATORS ARE PROCESSERS, EDUCATORS ARE PRISON OFFICERS.

\section{EDUCATOR ARE PRODUCERS}

This conceptual metaphor EDUCATORS ARE PROCESSERS concluded is widely demonstrated in several data of linguistic metaphors in English which is far more than in Chinese. In this conceptual cross-domain mapping, some concepts of the source PRODUCERS are drawn upon to account for relevant concepts in the target domain EDUCATORS. In the source domain PRODUCERS, some concepts PRODUSING, PREDETERMINED ACTIONS, RAW MATERIAL, PRODUCTS, ASSEMBLY LINES/FACTORY, etc., as are mapped onto the source domain EDUCATOR's concepts TEACHING, RESTRICTED TEACHING PATTERNS, EDUCATEES, ENVIROMENTS, etc.

(27) College is the grinding machine of the Mathematical Establishment, a conveyor belt that takes individuals from one cookie cutter to another so that the product comes within tight control limits out of the assembly line.

(28) Teachers have their sights set on the real goal: not to produce Ivy League graduates, but to encourage the development of naturally curious, confident, flexible, and happy learners who are ready for whatever the future has in store.

(29) Kids' hearts are malleable, but once they gel it's hard to get them back the way they were.

From (27) to (29), we will have a clear idea about why we can compare educators to producers. "produce" (28) and "malleable" (29) can be the demonstrations of concepts of the teaching process; "grinding machine" and "assembly line" (27) are compared to the teaching environment.

\section{EDUCATORS ARE PRISON OFFICERS}

There is no doubt that this is also a negative conclusion. In this conceptual metaphor EDUCATOR ARE PRISON OFFICERS, the target domain EDUCATOR is construed in terms of the source domain PRISON OFFICERS. PRISON OFFICERS are related to such concepts as PRISONS, PRISONERS, GUARDING PRISONERS, etc., as are mapped onto the concepts EDUCATORS, EDCATIONAL INSTITUTIONS, EDUCATEES, TEACHING, etc.

(30) Going to school is going to prison...you have about two weeks to establish your credibility, failing which And to these are necessarily added the time-serving priest or teacher, as the case may be, supported and protected by the government, to render the spirit of the people servile and make them docile under the yoke.

(31) Changes in curriculum and the monitoring of pupil progress have placed tremendous demands on teacher time and supervising out of school hours clubs and teams may feature low on priorities.

(32) Typically, the teacher will oversee the student's schedule, learning location, and pace. That requires weekly scheduling and daily monitoring of each student.

As mentioned above, we are able to conceptualize EDUCATORS AS PRISON OFFICERS due to the conceptual mappings from many sub-concepts of prison officers to those of educators. From (30) to ( 32), "yoke", "monitoring", and "oversee" can be compared to "guarding", which displayed that 4ducates are under control of educators in both knowledge and discipline. In (30), "prison" can be mapped onto the concept of some educational institutions, so prisoners are conceptually construed as "4ducates". The reason lies in its control on 4ducates.

\section{COGNitive Basis OF METAPHORS FOR EDUCATORS}

As to cognitive linguistics, the cognitive basis of metaphors is the image schema motivating metaphors and servers as the ground of metaphors (Johnson 1987; Lakoff 1987; Yu 1998; Kovesces 2010). Are there differences between the same conceptual metaphors shared by both Chinese and English? In order to answer these questions, we will explore them from the perspective of the cognitive basis of metaphors for educators and cultural cognitive approach to metaphors for educators.

\section{A. Embodied Experience and Image Schema}

According to experientialism in philosophy, human conceptual structures and systems are metaphorical essentially so we can present it in another way - thinking or cognition is metaphorical essentially (Yu 1998; Wen 2014). Since, our cognition comes from embodied experiences. Thus, the embodied experiential basis of metaphors is metaphors' cognitive basis. Through the conceptualizations of the bodily experiences, image schemas are pervasive, including CONTAINER SCHEMA, PATH SCHEMA, LINK SCHEMA, BALANCE SCHEMA, SCALARITY SCHEMA, OBJECTS SCHEMA, FORCES SCHEMA. Some others represent orientational and relational schemas, such as PART-WHOLE SCHEMA, CENTER-PERIPHERY SCHEMA, FRONT-BACK SCHEMA, and so on (Turner 1990).

Lakoff (1987a) claims that image schematic structure is a preconceptual structure in our embodied experiences so as to cause conceptual structure. However, because conceptual structures metaphors are metaphorical, and metaphors are ways of thinking which can be understood as conceptual structures as well. Thus, metaphors are on the basis of image schemas, or rather, the embodied experiences of image schemas are the cognitive basis of metaphors.

However, what is the embodied experiential basis or image schemas for the source domains occurring in those 
conceptual metaphors including GUIDE, GARDENER ARTIST, FEEDER, STUFFER, LIGHT SOURCE, ANIMAL, PROCESSER, JAILER? How are they functioning in our cognition? We will have a logical demonstration in the following part.

\section{B. Experiential Basis of Metaphors for Educators}

As has mentioned above, the cognitive basis of metaphors is the image schemas, so in order to provide a satisfying and convincing account for those questions raised above, in the first place, we have to generalize the commonest characteristics of educators in terms of these conceptual metaphors for educators: EDUCATORS ARE GUIDES, EDUCATORS ARE GARDENERS, EDUCATORS ARE ARTISTS, EDUCATOES ARE FEEDERS, EDUCATORS ARE STUFFERS, EDUCATORS ARE LIGHT SOURCES, EDUCATORS ARE ANIMALS, EDUCATORS ARE PRODUCERS, and EDUCATORS ARE PRISON OFFICERS, that is , "cause of change", or rather, "cause of change" refers to "cause of educatees' intellectual change". As a teacher, there must have numerous characteristics they are possessed of, however, to find the image schemas as cognitive basis of metaphor for educators, we can only resort to some commonest characteristics, and we have to try to highlight something and hide others. Thus, upon closer analysis, "cause of educatees' intellectual change" is evacuated.

Since all the nine conceptual metaphors for educators are very specific, so based on "cause of educatees' intellectual change" characteristic, they can further deduce some general metaphors as following: CAUSES OF CHANGE ARE CONTROL OF MOVEMENTS FROM ORIGINS TO DESTINATIONS, CAUSES OF CHANGE ARE CONTROL OF MOVEMENTS FROM SEEDS TO PLANTS, CAUSES OF CHANGE ARE CONTROL OF MOVEMENTS FROM RAW MATERIALS TO MASTERPIECES, CAUSES OF CHANGE ARE CONTROL OF MOVEMENTS FROM BEING STARVING TO BEING FULL, CAUSES OF CHANGE ARE CONTROL OF MOVEMENTS FROM BEING EMPTY TO BEING FILLED, CAUSES OF CHANGE ARE CONTROL OF MOVEMENTS FROM BEING DARK TO BEING BRIGHT, CAUSES OF CHANGE IS CONTROL OF MOVEMENTS FROM BEING FLOWERS TO FRUITS, CAUSES OF CHANGE ARE CONTROL OF MOVEMENTS FROM RAW MATERIALS TO PRODUCTS, CAUSE OF CHANGE ARE CONTROL OF MOVEMENT FROM BEING FREE TO IMPRISONED, all of which can be categorized into a more general conceptual metaphor: CAUSE OF INTELLECTUAL CHANGE ARE CONTROL OF MOVEMENTS FROM LOCATIONS/STATES TO LOCATIONS/STATES.

Lakoff (1993a, 1993b, 1994) and Yu (1998) emphasize one primary metaphors of the Event Structure Metaphor: CAUSES ARE FORCES (CONTROLLING MOVEMENT TO OR FROM LOCATIONS (STATES). Subsequently, the primary metaphor of all those conceptual metaphors above can be distilled in terms of CAUSES ARE FORCES, that is, CAUSES OF INTELLECTUAL CHANGE ARE FORCE (CONTROLLING MOVEMENTS FROM OR TO LOCATIONS/STATES). Moreover, according to Lakoff (1993a, 1993b, 1994) two particular systems to display a duality of the Event Structure Metaphor: location system and object system. Thus, in the location system, CAUSES OF INTELLECTUAL CHANGE ARE FORCES (CONTROLLING MOVEMENTS FROM OR TO LOCATIONS/STATES); In the object system, CAUSES OF INTELLECTUAL CHANGE ARE FORCES (CONTROLLING MOVEMENTS OF POSSESSION)( GIVING). Both of the two versions can be conceptualized mainly in terms of our sensorimotor schemas such as FORCE schema, SOURCE-GOAL schema, CONTAINER schema, UP-DOWN schema etc.

We often embody the experience of the performance of specific movements of us and something. Thus, in order to finish our movements, we will exert a force on our movements so as to enable us to reach the goal. This force derives from our sense of potential energy which is related to the performance of some task specific. Taking the mountain-climbing for example, we can climb the mountain from the root to the top because we have a potential force to control our movement to finish the task of climbing mountain. These experiences can abstract the FORCE schema (ENABLE schema and compulsory schema) (Evans \& Green, 2006), SOURCE-GOAL schema.

Based on our embodied experiences, a universal embodied experience "cause of change" in all the conceptual metaphors can be metaphorically mapped on the FORCE schema. Therefore, based on ENABLE schema, in the characterization of educators, they can be described as "enable to cause of change from origins to destinations" as exemplified by EDUCATORS ARE GUIDES; "enable to cause of change from seeds to fruits" in EDUCATORS ARE GARDENERS, "enable to cause of change from jade to masterpiece" in EDUCATORS ARE ARTISTS, "enable to cause of change from starving to being full" in EDUCATORS ARE FEEDER, "enable to cause of change from being empty to being filled" in EDUCATORS ARE STUFFERS, "enable to cause of change from being dark to being bright" in EDUCATORS ARE LIGHT SOURCES, "enable to cause of change from flowers to fruits" in EDUCATORS ARE ANIMALS, "enable to cause of change from raw materials to products" in EDUCATORS ARE PRODUCTS and "enable to cause of change from being free to being imprisoned" in EDUCATORS ARE PRISON OFFICERS. When we concentrate on the object system, we should understand "cause of intellectual change" from the perspective of movements of the possession, such as "taking away (pruning) trees' branches to change them to be straighter" in EDUCATORS ARE GARDENERS, "taking away crude jades' imperfections so as to change them to masterpiece" as is exemplified in EDUCATORS ARE ARTISTS.

According to daily bodily experiences, container as an image schema is rooted in human being's conceptualizations of experiences. As a container, it must be a bounded space with some materials in or out, thus, comparing to human's breath in or breath out, and eating or excretion, human bodies are conceived as contains as well not only for some 
physical "in or out", but also for some intellectual "in or out". Another property which has to mention is that containers are supposed to be full or empty, and unfilled or filled through the capacity of containers, which is like materials' state of rising-up and falling-down. Based on this embodied experience, educators" "cause intellectual change" characteristic can be mapped onto "cause the change of capacity of the container". "cause of change from being staving to being full" in EDUCATORS ARE FEEDERS, and "cause of change from being empty to being filled" in EDUCATORS ARE STUFFERS.

\section{Cultural COGNitive EXPlanations FOR MEtaphors FOR EduCATORS}

Based on cognitive basis of metaphors for educators above, we can find that all these image schemas are universal, which determines that there must be some conceptual metaphors for educators that are universal as well, all of which are on the basis of shared embodied experiences in similar cognitive model, especially those metaphors in general levels. Those metaphors that are in less general levels are not universal for their different embodied experiences. Many famous linguistics and anthropologists claim that our embodied experiences themselves are on the basis of cultural contexts (Csordas 1994; Strathern 1996; Quinn 1991). Since conceptual metaphors are conceptualized in terms of human embodied experiences as well, we establish the enterprise of metaphors culturally and socially. "Cultural models work for individuals and collective communities in shaping what people believe, how they act, and how they speak about the world and their own experiences." (Gibbs 1999: 154). Thus, in the final analysis, in educational contexts, some metaphors for educators are universal due to share embodied experiences molded by similar cognitive models (from a psychological perspective) while metaphors for educators which are specific are on the basis of cultural models (from a socio-cultural perspective).

\section{A. Cognitive Model for Educators}

Cognitive models are the stored cognitive representations pertaining to a certain field (Ungerer \& Schmid 2013), which is more individual. Therefore, among various cognitive models for educators, there must have a prototypical cognitive model for educators which are centered on a large number of cognitive models. In cognitive linguistics, prototype is not only regarded as "best example of a category" and "clearest cases of category membership", "most representative of things included in a class" or "central and typical members" (Lakoff 1986; Brown 1990) but more importantly also a psychological representations and cognitive reference point (Ungerer \& Schmid 2013). Thus, a prototypical cognitive model is mentally represented and cognitively refers to other cognitive models for the category EDUCATOR, and all conceptual metaphors for educators and other related concepts converge on a prototypical cognitive model or models for the category EDUCATOR. In the conceptual metaphors we conclude, all of them represent some similar and different cognitive models across cultures for educators. Therefore, in order to find out the prototypical cognitive model for educators, we have to resolve to the cognitive basis of metaphors educators. From the primary metaphor CAUSES OF INTELLECTUAL CHANGE ARE FORCE (CONTROLLING MOVEMENTS FROM OR TO LOCATIONS/STATES), we can draw a conclusion that educators are causes of intellectual change, but why do we deem educators as causes? Why do educatees have intellectual change? The reason is that educators cause educatees' intellectual change through the movement of knowledge.

Thus, we can outline a cognitive model for EDUCATORS, as is illustrated in Figure 1.

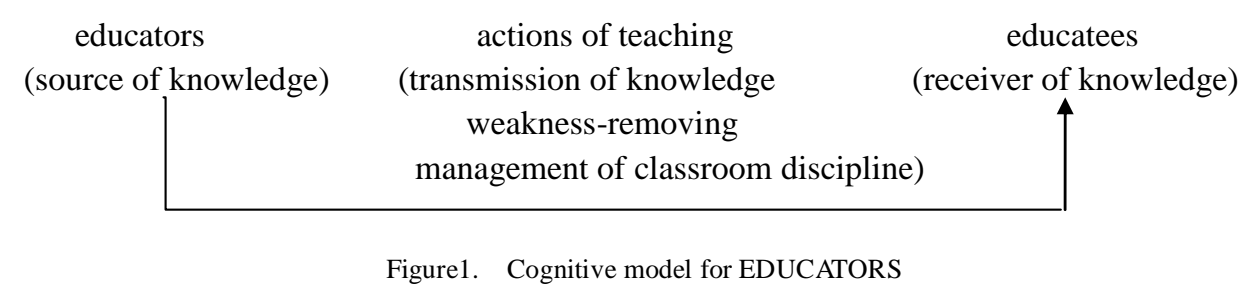

In this figure, "educators" are mainly understood metaphorically as "source of knowledge", "educatees" as "receivers of knowledge". Specifically, "educators" as "source of knowledge" make intellectual change of "educatees" as "receiver of knowledge" through actions of teaching which primarily include three aspects: transmission of knowledge, weakness-removing, and management of classroom discipline. For example, "transmission of knowledge" can be exemplified by EDUCATOES ARE FEEDERS, EDUCATORS ARE STUFFERS, etc., "weakness-removing” by EDUCATORS ARE GARDENERS, EDUCATORS ARE ARTISTS, etc., and "management of classroom discipline" by EDUCATORS ARE PRISON OFFICERS, etc. Subsequently, any other conceptual metaphor for educators around this prototypical cognitive model or these components is conceived as an educator. However, although all metaphors are metaphors for educators but the realizations of those mappings from different source domains to the same target domain, which are in specific level, are rooted in cultural variations.

\section{B. Explanations for Cultural Variations of Metaphors for Educators}

In those conceptual metaphors, a particular target domain EDUCATORS is conceptualized by a variety of source 
domains GUIDES, GARDENERS, ARTISTS, FEEDERS, STUFFERS, LIGHT SOURCES, ANIMALS, PRODUCERS and PRISON OFFICERS. In addition to universality, in educational contexts, there will be cultural variations in those metaphors for educators, some of which are common to both Chinese and English, some specific to Chinese and some specific to English. For example, in both Chinese and English educational contexts, the process of guiding is compared to the process of teaching; in Chinese educational context, regarding the process of lighting as teaching is not salient in English, while the conceptualization of educators as prison officers are especially prominent in English. Thus, we list a comparison between conceptual metaphors for educators, as is represented in Table 1.

TABLE 1

COMPARISON BETWEEN METAPHORS FOR EDUCATORS IN CHINESE AND ENGLISH EDUCATIONAL CONTEXTS

\begin{tabular}{lcc}
\hline \multicolumn{1}{c}{ Metaphors in both educational contexts } & $\begin{array}{c}\text { Metaphors in Chinese } \\
\text { educational context }\end{array}$ & $\begin{array}{c}\text { Metaphors in English } \\
\text { educational context }\end{array}$ \\
\hline EDUCATORS ARE GUIDES & + & + \\
EDUCATORS ARE GARGENER & + & + \\
EDUCATORS ARE ARTISTS & + & + \\
EDUCATORS ARE FEEDERS & + & + \\
EDUCATORS ARE STUFFERS & + & + \\
EDUCATORS ARE LIGHT SOURCES & + & - \\
EDUCATORS ARE ANIMALS & + & + \\
EDUCATORS ARE PRODUCERS & - & + \\
EDUCATORS ARE PRISON OFFICERS & - & + \\
\hline
\end{tabular}

According to Kovesces (2010)'s categorization of cultural variations, conceptual metaphors for educators is embedded in the following two likely possibilities:

a. Variation in particular elaborations of conceptual metaphors for educators.

b. Variation in potential sources domains, or the range of conceptual metaphors, for the target EDUCATORS.

\section{Variation in elaboration}

Variation in elaboration is a situation where the set of conceptual metaphors are shared by two different languages or cultures, but those metaphors are elaborated in different way. In the common cases of metaphors for educators in both Chinese and English educational contexts, EDUCATORS ARE GUIDES and EDUCATORS ARE ARTISTS are cases shared by both Chinese and English but are elaborated in different way. EDUCATORS ARE GUIDES in both Chinese and English share the same sub-cognitive basis for metaphors for educators that the cause of educatees' intellectual change are control of movements from origins to destinations, but they display huge differences in the representations of "guides" and process of guiding. Talking about representations of guides, guides are typically compared to many professions or entities such as "coxswain", "road metals", "north star", and "beacons" which are less salient using in English to describe a guide in this way. While English tends to apply those images like "compass", "bridge" and "party host" as guides but Chinese seldom use. Comparing those representations, those Chinese-specific "guides" emphasize its absolute leading even "holy" position, while, in English educational context, those qualities do not exist but highlight practical use much more. When it comes to the process of guiding, those Chinese-specific linguistic metaphors much more are teachers-centered but English-specific ones are particularly students-centered.

The reasons for these cultural variations have to come back to history, early in the Spring and Autumn and Warring Stage Period when educators are entitled as the embodiment of saints who are models of wisdom and morality and guiding people to be civilized under the influence of Confucianism. Confucius ever said that "Heaven having produced the inferior people, made for them rulers and teachers” (天降下民，作之君，作之師). Modern Chinese people inherit this attitude toward educators, regarding educators as guides which are represented by many absolute leading entities even shrouded in sort of "holy" atmosphere with centered position. As to English culture, numerous ideological emancipation movements have burst out since ancient time such as Renaissance Exists. English people are more likely to break with conventions in order to pursuit freedom, equality and individuality. Thus, they treat education as a process of individuality realizations. In class, educators are more likely like assistants to put students into the center so as to guide them to realize themselves, or rather, they guide students in the process of students' building of individualities.

Another conceptual metaphor shared by both English and Chinese EDUCATORS ARE ARTISTS illustrates something very interesting. In Chinese educational context, the source domain ARTISTS is confined to "craftsmen" especially for "jades" whereas in English educational context, the source domain ARTISTS points to a lot of conceptions such as "craftsmen" (especially "sculptors"), "entertainers" and "directors". The explanations for the differences lie in the following: since China has been through agricultural society for several thousand years, the productive forces level was very low in ancient times. Thus, people daily activities are inextricably bound up with nature and the objects of art are very limited so that the kinds of craftsmen are also few. Why people select jades as the commonest object? That is because jades are very rare and valuable. In addition, a good artifact of jade is from a crude jade to a masterpiece by chiseling repeatedly and carefully. Therefore, in Chinese educational context, people are inclined to compare educators to craftsmen and educatees to crude jades. In English culture, due to fast social productive force and high industrialization, especially after Industrial Revolution, people began to release the control of 
nature. Thus, based on various needs and desires, more professions appear so as artists.

\section{Variation in range}

Except for those cases shared by both Chinese and English, some ranges of conceptual metaphor are available mainly to Chinese or English. As to Chinese-specific conceptual metaphor EDUCATORS ARE LIGHTSOURCE, it seldom appears in English to describe educators. Otherwise, for those conceptions selected, most of which are candles, lights, reflecting the qualities of brightness, warmth and self-dedication. Another specific Chinese one EDUCATORS ARE ANIMALS also contains some animals that are widely regarded as the embodiments of diligence and self-dedication, such as "ox", "cow", "honey bees", and "silkworms".

On the whole, all those conceptions in two conceptual metaphors intentionally figure educators' noble moralities and huge responsibilities for whole society.

With the development of society, educators' role have gradually been transferred from saints to the figure of "public servant" since China's reform and opening up in 1980s. At that time, when the People's Republic of China was established, everything needs to be recovered, educators are laden with heavy responsibilities for education in new China. At that time, educators are taken for granted that they are supposed to have the spirit of dedication and character of diligence. Thus, many conceptions embodying the spirit of self-dedication are selected to be the metaphors for educators. That is why people are apt to choose "ox", "cow", "honey bees", and "silkworms" to compare to educators for they are all the representatives of self-dedication and make contributions to people and the world. While in English culture, educators are seldom endowed with self-dedication, for in English culture, unlike the worship of collectivism which emphasis self-dedication and contributions to the society in China, English culture is rooted in individualism which worships the development of selves.

Unlike China as an agricultural society for a long time, western countries began their industrialization from 1860s, and now industrialization of many western countries such as America and British is tremendously developed. Industrialization as a symbol of English culture, are rooted in western people's minds for industrialization changes people's material and spiritual life enormously and has affected every field of the society including education. Everything people need is produced from raw materials by producers with machines in assembly lines so western people are inclined to compare the process of producing to education. Because the process of industrialization in China is under developed, so that is why in English culture, people tend to use producers as educators and conceptual metaphor EDUCATORS ARE PRODUCERS appears in English educational context more frequently.

Talking about EDUCATORS ARE PRISON OFFICERS, the first thing we can figure out is "jails" and "prisoners", which are the working place and working objects for prison officers. In English culture, prison is frequently mentioned many literatures or movies for as we have mentioned before, freedom and individuality are people's value, thus, being a prisoner means being a man who is deprived of freedom and individuality and jail is a place one changing his state of being free to being imprisoned. Thus, prison officers in the jail are becoming a person who will control their freedom directly. Therefore, in English educational contexts, people who do not like school life will compare schools to jails due to the loss of their freedom and compare educators to prison officers due to their control on their freedom and individualities. In Chinese history, jails as a symbol of a society always exist, but why we seldom compare educators to prison officer? The reason must lie in our collectivism values as well.

\section{CONCLUSION}

In this paper, we have mainly explored metaphors for educators in both Chinese and English educational contexts from the perspective of cognitive basis, and cultural cognitive explanations. On the basis of numerous data of linguistic metaphors used in educational contexts, we find that some of them are common to both English and Chinese, and some of them are Chinese-specific and English-specific, as is presented in Table 2.

TABLE 2

CLASSIFICATION OF METAPHORS FOR EDUCATORS

\begin{tabular}{lll}
\hline Metaphors in both educational contexts & Metaphors in Chinese educational context & Metaphors in English educational context \\
\hline EDUCATORS ARE GUIDES & EDUCATORS ARE LIGHT SOURCES & EDUCATORS ARE PRODUCERS \\
EDUCATORS ARE GARDENERS & EDUCATORS ARE ANIMALS & EDUCATORS ARE TURNKEYS \\
EDUCATORS ARE ARTISTS & & \\
EDUCATORS ARE FEEDERS & & \\
EDUCATORS ARE STUFFERS & & \\
\hline
\end{tabular}

All those metaphors above are cognitive and cultural oriented. Metaphors for educators are derived from the primary metaphor EVENT STRUCTURE metaphor-CAUSE IS FORCE, which can be conceptualized mainly in terms of our sensorimotor schemas: FORCE schema, SOURCE-GOAL schema, CONTAINER schema, UP-DOWN schema etc. therefore, some metaphors especially those are in general level for educators share the same cognitive basis are universal, but for those metaphors which are in some specific levels, their differences are on the basis of cultural variations. We categorize the cultural variations of metaphors for educators in the following two aspects: 
a. Variation in particular elaborations of conceptual metaphors for educators. In the cases of metaphors for educators EDUCATORS ARE GUIDES and EDUCATORS ARE ARTISTS, are common to both Chinese and English educational contexts, but are elaborated in different way.

b. Variation in potential sources domains, or the range of conceptual metaphors. In the cases of metaphors for educators which are Chinese-specific and English-specific, LIGHT SOURCE and ANIMALS are specific to Chinese while PRODUCER and PRISON OFFICERS are specific to English.

\section{REFERENCES}

[1] Brown, C. H. (1990). A survey of category types in natural language. In S.L. Tsohatzidis (ed.), Meanings and prototypes: Studies in linguistic categorization, (p.17-47).London/New York: Routledge.

[2] Csordas, T. (1994). Embodiment and experience. New York: Cambridge University Press.

[3] Evans, V., \& Green, M. (2006). Cognitive linguistics: an introduction. Edinburgh: Edinburgh University Press.

[4] Gibbs, R. W., Jr. (1999). Taking metaphor out of our heads and putting it into the cultural world. In R. W. Gibbs \& G. Steen (eds.), Metaphor in Cognitive Linguistics (p.146-166). Amsterdam: John Benjamins.

[5] Johnson, M. (1987). The body in the mind: The bodily basis of meaning, imagination and reason. Chicago: University of Chicago Press.

[6] Kasten, I. (1998). Metaphor and teaching. In M. Hannula (ed.), Current state of research on mathematical beliefs V (pp. 36-42). U.S.: ERIC.

[7] Kövecses, Z. (2005). Metaphor in culture: Universality and variation. Cambridge: Cambridge University Press.

[8] Kövecses, Z. (2010). Metaphor: A practical introduction. Oxford: Oxford University Press.

[9] Lakoff, G., \& Johnson, M. (1980). Metaphors we live by. Chicago: University of Chicago Press.

[10] Lakoff, G. (1987). Women, fire, and dangerous things: What categories reveal about the mind. Chicago: University of Chicago Press.

[11] Lakoff, G., \& Turner, M. (1989). More than cool reason: A field guide to poetic metaphor. Chicago: University of Chicago Press.

[12] Lakoff, G. (1993a). The contemporary theory of metaphor. In A. Ortony (ed.), Metaphor and Thought (2nd edition) (pp.202-251). Cambridge: Cambridge University Press.

[13] Lakoff, G. (1993b). The metaphor system and its role in grammar. In U. Eco, M. Santambrogio \& P. Violi (eds.), Papers from the parasession on the correspondence of conceptual semantic and grammatical representations (pp.217-241). Chicago: Chicago Linguistic Society.

[14] Lakoff, G. (1994). What is a conceptual system? In W. F. Overton \& D. S. Palermo (eds.), The Nature and Ontogenesis of Meaning (pp.41-90). Hillsdale, N. J.: Erlbaum.

[15] Quinn, N. (1991). The Cultural Basis of Metaphor. In J. Fernandez (ed.), Beyond Metaphor: The theory of Tropes in Anthropology (pp.56-93). Stanford, Calif.: Stanford University Press.

[16] Strathern, A. (1996). Body thoughts. Ann Arbor: University of Michigan Press.

[17] Sweeter, E. (1990). From etymology to pragmatics. Cambridge: Cambridge University Press.

[18] Turner, M. (1990). Aspects of the invariance hypothesis. Cognitive Linguistics, 1, 247-255.

[19] Ungerer, F., \& Schmid, H. J. (2008). An introduction to cognitive linguistics (2nd Edition). Beijing: Foreign Language Teaching and Research Press.

[20] Wen Xu. (2014). Cognitive Foundation of Language. Beijing: Science Press.

[21] Yu, N. (1998). The Contemporary Theory of Metaphor: A Perspective from Chinese. Amsterdam: John Benjamins.

Mei Tao was born in Sichuan, China in 1987. She received her doctorate in English linguistics and literature from Southwest University.

She is engaged in post-doctoral studies in the education department at Southwest University while she is a lecturer in College of International Studies, Southwest University. Her research interests include culture, metaphor, education, and English language. 